\title{
A theoretical framework for investigating ecological problems associated with biodiversity conservation in national parks: A case of the Rwenzori Mountains National Park, Uganda
}

\author{
Moses Muhumuza ${ }^{1,2^{*}}$, Martie Sanders ${ }^{1}$, Kevin Balkwill ${ }^{1}$ \\ ${ }^{1}$ University of the Witwatersrand, Johannesburg, South Africa; ${ }^{*}$ Corresponding Author: musacot@gmail.com \\ ${ }^{2}$ Mountains of the Moon University, Fort-Portal, Uganda
}

Received 7 December 2012; revised 10 January 2013; accepted 4 February 2013

Copyright (C) 2013 Moses Muhumuza et al. This is an open access article distributed under the Creative Commons Attribution License, which permits unrestricted use, distribution, and reproduction in any medium, provided the original work is properly cited.

\begin{abstract}
Theoretical frameworks play a vital role in research, spelling out the constructs important in the research area, and the relationships between the constructs. An understanding of the theoretical constructs which underpin the research provides researchers with a framework, which enables them to understand when, how and why particular phenomena occur. Depending on the type of research, this either allows them to make reasoned predictions, which can be empirically tested during the research or gives direction for the research if it is open-ended and exploratory. Such frameworks not only guide the questions asked and the design of the research, but also help to interpret the data. If the situation being investigated is very complex, involving numerous interlinked variables, it is often difficult to identify a single theoretical framework that is suitable for a particular study. This article uses the case of human ecological behavioural problems associated with the conservation of biodiversity in the Rwenzori Mountains National Park, to show how a theoretical framework to investigate a complex situation was developed.
\end{abstract}

Keywords: Theortical; Framework; Ecological; Problems; Biodiversity; Conservation; Investigating; National Parks; Rwenzori

\section{THE IMPORTANCE OF THEORIES AND THEORETICAL FRAMEWORKS IN RESEARCH}

Researchers cannot begin their work without an un- derstanding of the concepts being investigated, or an understanding of the generalizations which have emerged from previous research. Researchers usually start their research projects by thoroughly reading the literature about the constructs relating to the research and how these constructs are interlinked. Such constructs and their interrelationship may be presented in the form of a theory, which Kerlinger [1] explains as "a set of interrelated constructs (concepts), definitions, and propositions that present a systematic view of phenomena by specifying relations among variables, with the purpose of explaining and predicting the phenomena” (p. 9). Maxwell [2] argues that every research design needs "some" theory of the phenomena under study even if it is only a commonsense one, to guide the other design decisions researchers make.

Researchers often identify with a particular theory or theories which influence their point of view about the research they conduct [3]. Although theories provide a new way of seeing things, their purpose goes beyond just understanding the constructs being investigated [4]. Theory provides explanations, understanding, prediction, and analysis of issues emerging from research [1]. Theory influences what researchers notice, coloring their perceptions and hence their decisions. Researchers use theories to provide a rationale for their work, and according to Caliendo and Kyle [5], this is what distinguishes scholarly work from journalism. More importantly, according to Maxwell [2], one of the four sources that researchers use to construct theoretical frameworks is existing theory. Therefore two or more theories may be developed into a theoretical framework.

A theoretical framework is defined as "a visual or written product, one that explains, either graphically or 
in narrative form, the main things to be studied, the key factors, concepts, or variables and the presumed relationships among them" [6, p. 18]. The terms "theoretical frameworks" and "conceptual frameworks" are used synonymously in literature [2,7]. For consistence, the phrase "theoretical framework" is used in this article.

The importance of theoretical frameworks in research has been extensively documented in literature. Theoretical frameworks enable researchers to form a foundation for their points of view and to critique other researchers when reviewing literature [8]. Theoretical frameworks also influence the steps researchers go through while investigating a particular problem [9], and in guiding the choice of a suitable research design [10]. In addition to their explanatory power, theoretical frameworks have predictive value, which helps researchers to make logical predictions and thus ask appropriate research questions [4]. Theoretical frameworks are also vitally important in providing direction for interpretation of the data [11,12]. A well articulated theoretical framework allows readers to see the assumptions which underpin the research, as well as whether the subsequent links between questions, design, and analysis of data are logical and cohesive [5], hence enabling readers to judge the quality of the work.

\section{LOCATING A SUITABLE THEORETICAL FRAMEWORK}

When research involves a situation that is complex, a multitude of interlinked variables in the problem that researchers are investigating often make it difficult for them to find a single theory or theoretical framework to underpin their particular study [13]. In such a situation, Abd-El-Khalick and Akerson [13], claim that researchers take varying options depending on the type of research. Some researchers simply describe a number of disconnected theories which are relevant to their research. Other researchers link various theories together into a single but multifaceted web of ideas in an effort to form a unified framework to guide their study. And other researchers choose a theory that is not entirely appropriate or adequate, and build on it until it is a satisfactory framework to guide their research [13]. However, a number of steps are taken to develop a single theory into a satisfactory framework.

\section{AIM OF THIS ARTICLE}

In addition to discussing the importance of theories and theoretical frameworks in research, the aim in this article is to describe how a theoretical framework was developed from a single theory and used to investigate a complex ecological problem associated with biodiversity conservation in the Rwenzori Mountains National Park.

\section{THE CONTEXT IN WHICH THE THEORETICAL FRAMEWORK WAS DEVELOPED}

The framework was intended to facilitate an investigation of a complex human ecological situation associated with the conservation of biodiversity in the Rwenzori Mountains National Park. The Rwenzori Mountains National Park is located north of the equator on the border adjoining the Democratic Republic of Congo. In 1941 the central forest reserve under the jurisdiction of the forest department of Uganda deemed the conservation of the Rwenzori Mountains important because the mountains have a rich biodiversity, including rare, globally threatened, and endemic species of plants and animals [14]. The mountainous terrain makes the area a fragile ecosystem prone to degradation due to increase in human population in the mountains [15].

Prior to 1941 the entire Rwenzori Mountains were accessible to local people. Whether or not local people had a mechanism of conserving biodiversity in the Rwenzori Mountains prior to 1941 is a matter for debate, an issue beyond the scope of this article but has been presented and discussed in Muhumuza et al. (in prep.). However, in 1941, part of the Rwenzori Mountains was designated as forest reserve [16]. Hunting of animals and harvesting of timber in the reserve were prohibited, but traditional activities such as medicine collection, use of foot paths in the reserve, and performance of traditional rituals in some areas of the reserve were permitted [16]. In 1991 the conservation status of the forest reserve was upgraded to a national park, and the boundaries of the forest reserve were extended to create the Rwenzori Mountains National Park. More stringent controls over the use of the resources in the park were put in place. Access to park resources was declared illegal, and the use of foot paths in the park that enabled local people to access different areas in the mountains was prohibited [17].

Despite these rules, a number of practices, although now illegal continued to occur. These countered efforts to conserve the park. Some of the illegal practices included harvesting of park resources by the local people [18]. Communities bordering the park resisted the attempts by the park's administration to prevent the illegal activities in the park $[19,20]$. The resistance caused a conflict of interests between the local community for the need to access resources in the park and the administration of the park for the need to conserve biodiversity in the park.

In order to address these problems, the Rwenzori Mountains National Park administration implemented community-based conservation initiatives. Some of these initiatives included implementing environmental education programmes, giving $20 \%$ revenue from tourism to the local people for infrastructural development, giving 
jobs to poachers who voluntarily surrendered to the park staff, and allowing some local leaders to be part of the Park Management Committee [19]. According to Tumusiime [17], collaborative resource use agreements were also implemented in some parishes neighbouring the Rwenzori Mountains National Park.

However, recent studies [17,21] have reported that despite these initiatives, local people have continued to oppose rules governing the use of park resources and to clandestinely conduct illegal activities in the park. Local people have encroached on the park land for cultivation [21]. Ernst [21] claims that there are some ethnic tensions that arose as a consequence of establishing the Rwenzori Mountains National Park. The establishment of the national park has led to income disparity among the people and limited attainment of development goals by the majority of the people [21].

These problems mean that the conservation of biodiversity in the Rwenzori Mountains National Park could be at risk. Before the problems can be addressed, their nature, extent, root causes and the context in which they occurred needed to be fully investigated.

A theoretical framework to guide an investigation into these problems was needed. This is because the problems associated with biodiversity conservation in the Rwenzori Mountains are social (associated with characteristics and organization of the local community). Unlike purely scientific studies, an investigation of social issues requires a theoretical framework. Factors responsible for the success and failure of conserving biodiversity in national parks in Africa in various contexts are socio-economic and cultural in nature (Muhumuza et al., in press). Despite this, the conservation of biodiversity in national parks has been the domain of scientists who aim to understand the biology of species and habitats they wish to conserve. As shown in Figure 1, sustainable use of resources is a confluence of socio-cultural, economic and ecological factors.

Newing [23] points out that although it is essential to understand habitats and species, it is not enough for conservation given that problems associated with conservation of biodiversity in many national parks are social rather than ecological. Newing [23] claims that at a more theoretical level, social issues in biodiversity conservation are fragmented and not well understood.

Approaches often used in biology to investigate problems associated with biodiversity conservation may not be feasible in investigating social problems impacting on biodiversity conservation initiatives in national parks. "The dominant approach in natural sciences is to come up with a hypothesis and then design a way of to 'prove' (or at least 'test') it” [23, p. 5]. Although hypothesis testing encourages clear thinking and understanding of a situation by breaking complex phenomena into theircomponents, it may not be feasible in research that in-

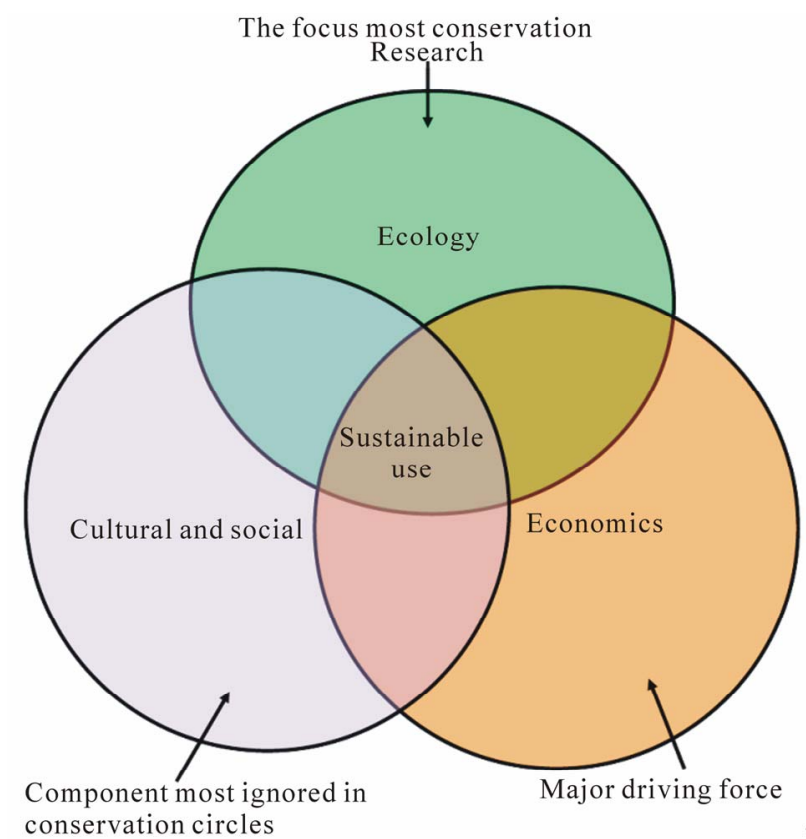

Figure 1. The confluence of socio-cultural, ecological and economic factors in sustainable resource use (adapted from [22])

volves social issues. It is impossible to break the "social world" into a set of discrete, tightly defined elements. In the social world, things are interlinked and if they are to be understood, they must be studied in that way [24]. This makes the investigation of problems in the Rwenzori Mountains complex necessitating a holistic approach. Therefore, developing a theoretical framework that would direct an appropriate investigation into these problems was important.

\section{THE STARTING POINT FOR DEVELOPING THE THEORETICAL FRAMEWORK}

Due to the complex nature of problems in the Rwenzori Mountains National Park, it was not possible to locate a suitable theoretical framework to guide the research into the identified problems and to facilitate adequate explanation of the data. However, because the conservation problems in the Rwenzori Mountains National Park were social and closely associated to human behaviour, psychological theories explaining factors that influence human behaviours were considered to be useful as a starting point to develop a theoretical framework to guide the investigation into these problems.

Various psychological theories attempt to identify and explain factors that influence human behavior. Some of the commonly encountered theories include; environmental citizenship behavioral model [25], value belief norm model [26], reasonable person model [27], systems thinking, described by Checkland [28], significant life 
experiences [29], Theory of Planned Behavior [30], elaboration likelihood model of persuasion [31], motivational theories such as Maslow's hierarchy of needs described in Decker, Brown \& Siemer [32], stages of change [33], diffusion of innovation [34], and social learning theory [35]. There is no single best theory among these theories, but different situations may dictate the suitability of one theory over the other.

Because the problems in the Rwenzori Mountains National Park involved anti-conservation behaviours, an understanding was required of the reasons for the choices made by the local communities, and the factors that underpin these choices. From the history of the Rwenzori Mountains and the Rwenzori Mountains National Park, local people's behavioural choices and their intention to behave the way they do are products of traditional beliefs and people's attitude towards the existence of the park as well as cultural attachment to some places in the park. This makes the Theory of Planned Behaviour (discussed in detail in the next section) the most suitable not only as a starting point to develop the theoretical framework to guide the research, but also as a basis for identifying factors influencing conservation choices made by individuals in the Rwenzori Mountains. The suitability of the Theory of Planned Behaviour is supported by Chao [36] who found that the predictor in the Theory of Planned Behaviour explained much more variance in behavioral intentions that those in reasonable person model. If the factors influencing the behavioral intentions are identified, they could be the logical targets of conservation strategies that aim to promote pro-conservation behaviour amongst local people living near the Rwenzori Mountains National Park.

\subsection{The Theory of Planned Behaviour}

The Theory of Planned Behaviour [30] is a theory for systematically identifying the determinants of people's behaviours. The definitions of the main terms used in the Theory of Planned Behaviour are shown in Table 1.

According to the Theory of Planned Behaviour (Figure 2), the immediate determinant of behaviour is the

Table 1. Definition of key terms used in the Theory of Planned Behaviour (Source: Concise Oxford English Dictionary $11^{\text {th }}$ Edition)

\begin{tabular}{|c|c|}
\hline Attitude & A settled way of thinking or feeling. \\
\hline Behaviour & $\begin{array}{l}\text { The way in which an animal or } \\
\text { person respodents to a situation or stimulus. }\end{array}$ \\
\hline Belief & $\begin{array}{l}\text { An acceptance that something exists or is true, especially } \\
\text { one without proof. Or firmly held opinion or conviction. }\end{array}$ \\
\hline Intention & $\begin{array}{l}\text { Conceptions formed by } \\
\text { directing the mind toward an object. }\end{array}$ \\
\hline Knowledge & $\begin{array}{l}\text { Information and skills acquired } \\
\text { through experience or education. }\end{array}$ \\
\hline Norm & A required or accepted standard. \\
\hline
\end{tabular}

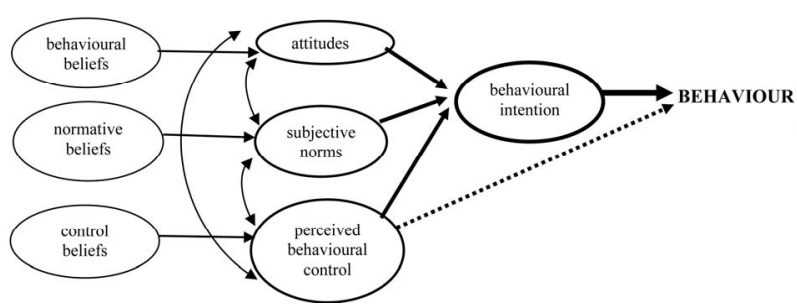

Figure 2. Representation of the Theory of Planned Behaviour source: [30].

individual's intention to perform or not to perform that behaviour. Intentions are in turn, influenced by three factors (attitudes, subjective norms and perceived behavioral control) and each of the three factors is affected by a set of beliefs [30]. The theory of planned behaviour has been used as a framework in various studies under different context [37-40].

The factors specified in the theory of planned behaviour and how they are relevant to the situation in the Rwenzori Mountains National Park have been elaborated below:

- Attitudes about the behaviour (favourable or unfavorable evaluations of the behaviour), are affected by behavioural beliefs (what people believe about the behaviour) [41]. In context of the problems in the Rwenzori Mountains National Park, beliefs held by individuals could affect their attitude towards the Rwenzori Mountains National Park. Attitudes and beliefs seem to be important factors to investigate to understand why individuals show particular behaviours. In the case of the Rwenzori Mountains, special focus was given to "indigenous beliefs" " that might affect attitudes on the use of resources in the park. Ogwang \& DeGeorges [42] claim that people in the Rwenzori Mountains have strong indigenous beliefs associated with the mountains. "Much of their folklore revolves around the 'old man of the mountain' and his son the one legged 'Shepherd' to whom sacrifices must be made prior to the hunt” [42, p. 40]. More recently, Starcey [43] reported that people who dwell in the Rwenzori Mountains believe that resources in the mountains are owned and controlled by the mountain gods. Such beliefs may be related to the real or perceived outcome of how resources are to be used by an individual. If the outcome is favorable and satisfying the needs of the individual, then the individual is likely to use park resources in that particular

\footnotetext{
${ }^{1}$ The use of the phrase "indigenous beliefs" in the context of this article is based on a definition by Lindsay [44] which refer to assumptions, theories, explanations and conclusions which local people in a specific area traditionally use as frameworks to help make sense of their experiences. Beliefs often become so ingrained, due to repeated situations that seem to "prove" their legitimacy, that people may confuse them with knowledge [45].
} 
way. In this case, how the individual uses the resources is a factor of the individual's beliefs about the "rewardibility" of a particular way the resource is used.

- Subjective norms (perceptions of social pressures to perform or not to perform a behaviour), are affected by normative beliefs (typical beliefs of the community or of the people important to the individual) [41]. In the Rwenzori Mountains, individuals exist within a community, and may have beliefs about community norms and how the community will judge anyone harvesting resources from the park. In this context, normative beliefs are beliefs of individuals about whether people important to them or the Rwenzori Mountains National Park community in which they live approve or disapprove them to use park resources in a particular way. For example, one aspect that may influence resource use is the gender of the resource user. Men and women collect and control resources differently [46]. Leach [47] reported that hunting of animals in the West African forests was done by males and not females. Therefore, a female may not engage in hunting if hunting is against the norms and values of the community in which she lives. In such a case, how an individual uses the resources is a function of social pressures on his or her way of using the resource. Therefore, if an individual in the Rwenzori Mountains believes that the community or people important to him or her approve the way he or she uses the resource, the individual is more likely to use the resource in the park in that particular way.

- Perceived behavioural control (perceptions of whether individuals can control the behaviour), are affected by control beliefs provided that individuals do have actual control. Individuals who feel that they are in control are more likely to perform the behavior than those who believe that outside factors control their behaviour. In the context of the Rwenzori Mountains, beliefs of an individual about whether he or she is in control of the way he or she chooses to use the resources in the park may affect how that individual uses resources. Such beliefs influence the individual's perception of whether he or she is in control of the way of using the resources in the park. For instance, individuals in the Rwenzori Mountains believe that before a hunt, sacrifice must first be offered to the god of animals [42]. If the individual believes that he or she is capable of offering the sacrifice, then he or she is likely to feel in control and hence more likely to hunt. In such a case, beliefs are a function of the individual's capability, skills, tools and expertise that are required to facilitate successful usage of the resource in a way he or she has chosen.

\subsection{Limitations of Single Theories in Guiding Complex Investigations: A Case of the Theory of Planned Behaviour}

Using existing theory as a basis of a theoretical framework has both advantages and pitfalls in qualitative research. According to Maxwell [2], one of the two ways in which qualitative researchers often risk in using existing theory as frameworks is by relying too heavily and uncritically on one theory. Therefore, although the Theory of Planned Behavior could considerably guide investigation into the problems associated with biodiversity conservation in the Rwenzori Mountains National Park, it could not adequately explain some of the conservationrelated behaviours of people in the Rwenzori Mountains. Firstly, beliefs are not the only factors that affect an individual's attitude. Knowledge acquired by individuals may also influence their attitude about a particular behaviour. For instance, when an individual acquires knowledge about the environment, that knowledge may influence that individual's attitude toward environmental protection [48]. The Theory of Planned Behaviour does not include the factor of knowledge. Secondly, the Theory of Planned Behaviour is a psychological model dealing with attitudes and beliefs in the minds of individuals (referred to as "internal milieu”) and does not refer to actual practices of an individual in the community. The individual's beliefs, attitudes and perceptions may not match reality and even if they do, they may not necessarily translate into behaviour. Thirdly, the Theory of Planned Behaviour does not consider external factors (factors in the environment, referred to as "external milieu”) which might affect behaviours. These three short comings make the Theory of Planned Behaviour inadequate as a framework to guide investigations of problems associated with biodiversity conservation in the Rwenzori Mountains National Park. Therefore, other factors were introduced in the Theory of Planned Behaviour to make it a suitable theoretical framework to guide the investigation into problems associated with biodiversity conservation in the Rwenzori Mountains National Park.

\subsection{How the Theory of Planned Behaviour Was Made into an Appropriate Theoretical Framework for This Study}

The three shortcomings in the Theory of Planned Behaviour as a framework were addressed by adding other factors as shown in Figure 3. As the first step toward the adaptation of the Theory of Planned Behaviour into a suitable framework, the factor of knowledge as a function of behaviour was introduced. According to Kaplan [27], individuals make decisions that govern behaviour based on their knowledge. Knowledge acquired by an- 


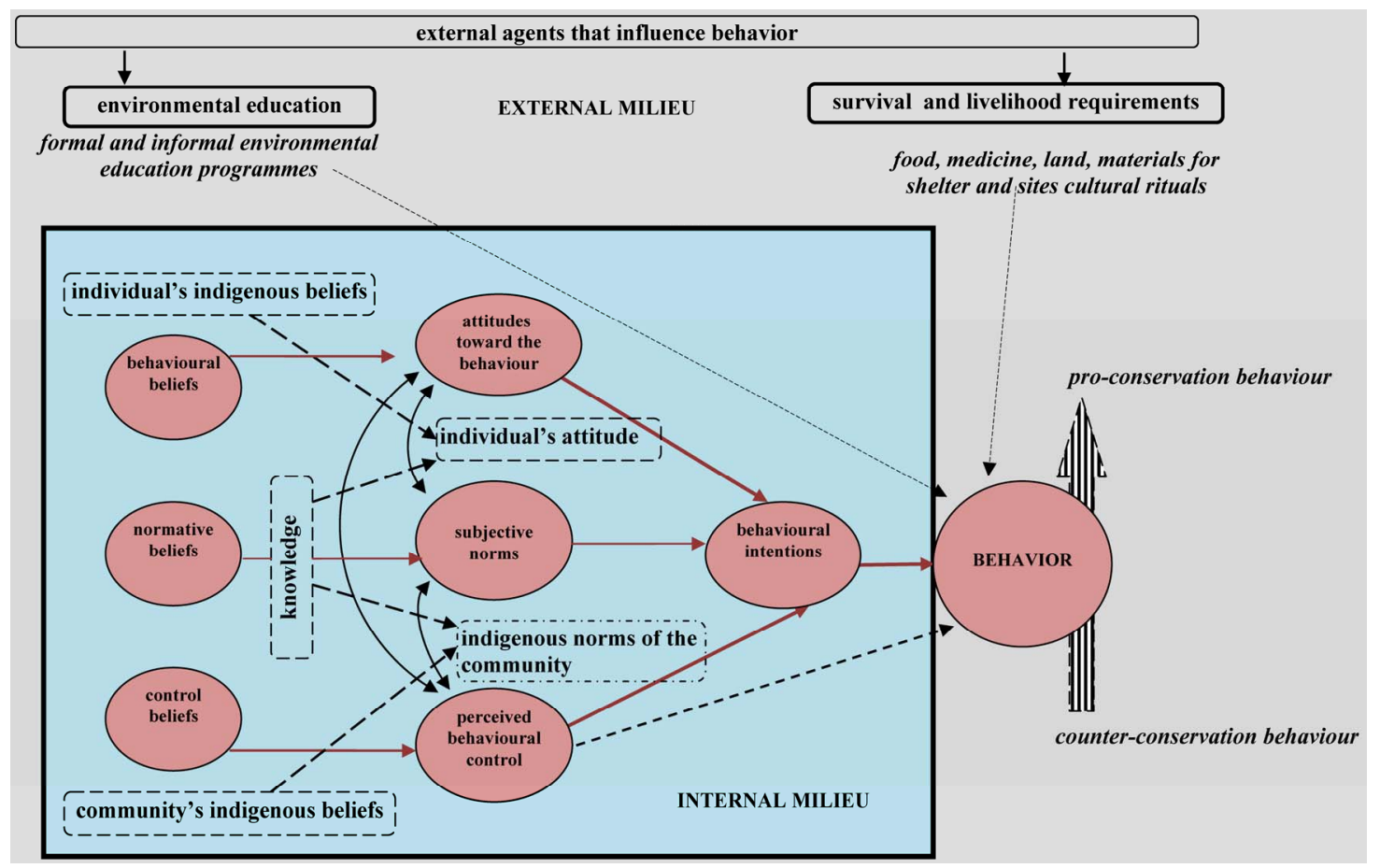

Figure 3. A conceptual framework for guiding an investigation into problems associated with conservation of biodiversity in this study.

individual may affect the attitude of that individual toward natural resource use and conservation. Knowledge could lead to both pro-conservation and ant-conservation behaviours. In some cases, the more knowledge people have about environmental issues, the more helpless they may feel and give up doing anything to protect the environment [49]. A form of knowledge that could influence an individual's behaviour in local traditional communities such as the Rwenzori Mountains could be contemporary scientific knowledge or traditional ecological knowledge.

Various studies (both theoretical and empirical) have argued that traditional ecological knowledge among traditional communities influences the way they use natural resources [50-53]. A study by Iaccarino [51] concluded that through traditional ecological knowledge people may conceptualize empirical observations to better understand nature, and thus interpret and predict it. Although some authors who have lived amongst the Rwenzori Mountain people [42,54,55] claim that local people in the Rwenzori Mountains have traditional ecological knowledge that influences the way they use resources, no studies so far have been conducted to investigate how that knowledge influences pro-conservation or counter-conservation behaviour of people living near the Rwenzori Mountains National Park. According to Foltz [56], an investigation on how traditional ecological knowledge influences conservation behaviour may help to understand why local people use natural resources in particular ways. Therefore it was necessary to add this factor in the Theory of Planed Behaviour.

As a second step, toward adaptation of the Theory of Planned Behaviour into a suitable theoretical framework, two external factors that could potentially influence the conservation behaviors of people in the Rwenzori Mountains were added. One of the factors is the livelihood and survival requirements of the local people from the park. Various studies show that local people depend on protected areas resources for livelihood and survival [57-59]. However, dependence on resources from protected areas varies among individuals and communities [59]. For instance, a study by Coulibaly-Lingani [60] demonstrated that resources people obtained from forests in Burkina Faso influenced their participation in forest management programmes. This means that different communities and individuals have varying reasons for their dependence on protected area resources. In the Rwenzori Mountains, local people obtain resources from the park for livelihood and survival [17]. However, Tumusiime [17] do not state the resources people get from the park and the reasons why people get those resources, and what factors other than lack of assets and alternative sources of income influence people's dependence on the Rwenzori Mountains National Park. For this reason, it was necessary to include the aspect of survival and livelihood requirements of local people into the theoretical framework.

The second external factor that was added to the The- 
ory of Planned Behaviour was environmental education. The essence of environmental education is that people should be educated about services that ecosystems provide and that once they know the value of environmental services, they may use the environment in a sustainable manner [48]. In the Rwenzori Mountains Environment Education Strategy (2004), it was stated that local people neighbouring the Rwenzori Mountains National Park have received environmental education. However, given that people continued to conduct illegal activities and actively resist park rules necessitated an investigation into the nature and extent of environmental education the people had received. Based on Jacobson [48] it would be expected that people in the Rwenzori Mountains would show pro-conservation behaviours toward the Rwenzori Mountains National Park staff if they had adequate environmental education. Therefore, it was also important to find out why despite provision of environmental education to people in the Rwenzori Mountains, they have persistently conducted clandestine activities in the park that were considered by the park administration illegal.

\section{CONCLUSIONS}

Theoretical frameworks play a vital role in research. They help researchers to spell out important constructs in research and the relationships between the constructs. However, when the situation being investigated is complex, researchers often face a problem of locating a suitable theoretical framework. In such circumstances, it is helpful to use an existing theory and develop it into a theoretical framework to guide the study. How this can be done using the Theory of Planned Behavior [30] as a starting point has been described in this article using the example of problems associated to biodiversity conservation in the Rwenzori Mountains National Park.

\section{REFERENCES}

[1] Kerlinger, F.N. (1986) Foundations of behavioral research. Holt, Rinehart and Winston publishers, Orlando.

[2] Maxwell, J.A. (2005) Qualitative research design: An interactive approach. SAGE, California.

[3] Ingelse, K. (1997) Theoretical frameworks. Northern Arizona University NAU OTLE Faculty Studio (online teaching resources).

[4] Wellington, J. (2000) Educational research: Contemporary issues and practical approaches. Continuum, London.

[5] Caliendo, S. and Kyle, W. (1996) Establishing the theoretical frame. Journal of Research in Science Teaching, 33, 225-227.

[6] Miles, M.B. and Huberman, A.M. (1994) Qualitative data analysis: An expanded sourcebook. SAGE, London and Thousand Oaks.

[7] Jabareen, Y. (2009) Building a conceptual framework:
Philosophy, definitions, and procedure. International Journal of Qualitative Methods, 8, 49-62.

[8] Tuckman, B. (1999) Conducting educational research. Harcourt Brace College Publishers, Fort Worth.

[9] Sekaran, U. (2000) Research methods for business. John Wiley \& Sons, New York.

[10] Camp, W.G. (2001) Formulating and evaluating theoretical frameworks for career and technical education research. Journal of Vocational Education Research, 26, 117. doi:10.5328/JVER26.1.4

[11] Elliott, J. (2005) Conceptual/operational frameworks. Workshop Paper Presented at the Association of International Agricultural and Extension Education conference, San Antonio, 12-15 July 2005.

[12] Radhakrishna, R.B., Yoder, E.P. and Ewing, J.C. (2007) Strategies for linking theoretical framework and research types. Proceedings of the 2007 AAAE Research Conference, Pennsylvania State University, 692-694.

[13] Abd-El-Khalick, F. and Akerson, V. (2007) On the role and use of "theory" in science education research: A response to Johnston, Sutherland, and Sowell. Science Education, 91, 187-194. doi:10.1002/sce.20189

[14] Howard, P.C. (1991) Nature conservation in Uganda's tropical forest reserves. International Union for Conservation of Nature and Natural Resources, Gland and Cambridge.

[15] Plumptre, A.J., Behangana, M., Davenport, T.R.B., Kahindo, C., Kityo, R., Ndomba, E. and Eilu, G. (2003) The biodiversity of the Albertine Rift. Wildlife Conservation Society, Kampala.

[16] McCall, D. (1996) Conservation and management of the Rwenzori Mountains. In: Osmaston, H., Tukahirwa, J., Basalirwa, C. and Nyakana, J., Eds., The Rwenzori Mountains National Park, Makerere University, Kampala, 3457.

[17] Tumusiime, D.M., Vedeld, P. and Gombya-Ssembajjwe, W. (2011) Breakingthe law? Illegal livelihoods from a protected area in Uganda. Forest and policy economics, 13, 273-283. doi:10.1016/j.forpol.2011.02.001

[18] Loefler, I. (1997) Protected areas programme, Rwenzori Mountains National Park. Kampala, Uganda.

[19] Rwenzori Mountains Environmental Conservation Education Strategy (2004) A policy document. District local governments of Kasese, Kabarole and Bundibugyo, The Rwenzori Mountains National Park, and World Wildlife Fund.

[20] Tamale, S.E. and Nzirambi, M.K. (1996) Local participation in the management and decision making of Rwenzori National Park. In: Osmaston, H., Tukahirwa, J., Basalirwa, C. and Nyakana, J., Eds., The Rwenzori Mountains National Park, Makerere University, Kampala, 112126.

[21] Ernst, S. (2011) Uganda Consequences of the establishment of Rwenzori Mountains National Park. Geographische Rundschau, 63, 57-63.

[22] Martin, R.B. (1994) Alternative approaches to sustainable use: What does and does not work. Paper presented at the conference of conservation through sustainable use of 
wildlife. University of Queensland, Brisbane.

[23] Newing, H. (2011) Conducting research in conservation: a social science perspective. Routledge, England.

[24] Blaikie, N. (1993) Approaches to social equity. Polity press, Cambridge.

[25] Hungerford, H.R. and Volk, T.L. (1990) Changing learner behaviour through environmental education. Journal of Environmental Education, 21, 8-22.

[26] Stern, P.C. (2000) Toward a coherent theory of environmentally significant behaviour. Journal of Social Issues, 56, 322-348. doi:10.1111/0022-4537.00175

[27] Kaplan, S. (2000) Human nature and environmentally responsible behaviour. Journal of Social Issues, 56, 491508. doi:10.1111/0022-4537.00180

[28] Checkland, P. (1993) Systems thinking, systems Practice. Wiley publishers, United Kingdom.

[29] Chawla, T. (1998) Significant life experiences revisited: A review of research on sources of environmental sensitivity. Environmental Education, 4, 369-382. doi:10.1080/1350462980040402

[30] Ajzen, I. and Madden, T. (1986) Prediction of goal-directed behaviour: Attitudes, intentions and perceived behavioural control. Journal of Experimental Social Psychology, 22, 453-474. doi:10.1016/0022-1031(86)90045-4

[31] Petty, R.E. and Priester, J.R. (1994) Mass media attitude change: Implications of the elaborate likelihood model of persuasion. In: Bryant, J. and Zillman, D., Eds., Media Effects: Advances in Theory and Research, Lawrence Erlbaum, Hillsdale, 91-122.

[32] Decker, D.J., Brown, T.L. and Siemer, W.F. (2001) Human dimension of wildlife management in North America. The Wildlife Society, Bethesda.

[33] Prochaska, J.O., DiClemente, C.C. and Norcross, J.C. (1992) In search of how people change: Applications to addictive behaviours. American Psychologist, 47, 11021114. doi:10.1037/0003-066X.47.9.1102

[34] Rogers, E.M. (1995) Diffusion of innovations. Free Press, New York.

[35] Bandura, A. (1997) Self efficacy: The exercise of control. W.H. Freeman and Company, New York.

[36] Chao, Y. (2012) Predicting people's environmental behaviour: Theory of planned behaviour and model of responsible environmental behaviour. Environmental Education Research, 18, 437-461. doi:10.1080/13504622.2011.634970

[37] Borzekowski, D. (2011) Planning to hook up: Using the theory of planned behavior to explain concurrency intentions among youth from three countries. Journal of Adolescent Health, 48, 81-112. doi:10.1016/j.jadohealth.2010.11.229

[38] Chen, T. and Chao, S. (2011) Habitual or reasoned? Using the theory of planned behavior, technology acceptance model, and habit to examine switching intentions toward the public. Traffic Psychology and Behaviour, 14, 128-137. doi:10.1016/j.trf.2010.11.006

[39] Mahmud, F. and Osman, R. (2010) The determinants of recycling intention behavior among the Malaysian school students: An application of theory of planned behaviour. Procedia-Social and Behavioral Sciences, 9, 119-124. doi:10.1016/j.sbspro.2010.12.123

[40] Norman, P. (2011) The theory of planned behavior and binge drinking among undergraduate students: Assessing the impact of habit strength. Addictive Behaviors, 36, 502-507. doi:10.1016/j.addbeh.2011.01.025

[41] Ajzen, I. (1991) The theory of planned behaviour. Organizational Behaviour and Human Decision Processes, 50, 179-211. doi:10.1016/0749-5978(91)90020-T

[42] Ogwang, D. A. and De Georges, P.A. (1992) Community participation in interactive park planning and the privation process in Uganda's National parks. Uganda National Parks and the United States Agency for International Development.

[43] Starcey, T. (2003) Tribe: The hidden history of the Mountains of the Moon. Stacey International, London.

[44] Lindsay, J. (1998) Designing legal space: Law as an enabling tool in community-based management. International CBNRM Workshop, Washington DC, 10-14 April 2003.

[45] Sentwali, B.R. (1997) Epistemology from an Afrocentric perspective: Enhancing black students' consciousness through an Afrocentric way of knowing. University of Nebraska-Lincoln, Lincoln.

[46] Agrawal, B. (1997) Environmental action, gender equity and women's participation. Development and Change, 28, 1-44. doi:10.1111/1467-7660.00033

[47] Leach, M. (1991) Endangered environments: Understanding natural resource management in the West African forest zone. IDS Bulletin, 22, 17-24. doi:10.1111/j.1759-5436.1991.mp22004004.X

[48] Jacobson, K.S., McDuff, M.D. and Monroe, C.M (2006) Conservation education and outreach techniques. Oxford University press, England. doi:10.1093/acprof:oso/9780198567714.001.0001

[49] Levin, G. (1993) Too green for their own good. Advertising Age, 64, 29-42.

[50] Antons, C. (2010) The role of traditional knowledge and access to genetic resources in biodiversity conservation in Southeast Asia. Biodiversity Conservation, 19, 1189-1204. doi:10.1007/s10531-010-9816-y

[51] Iaccarino, M. (2003) Science and culture. EMBO, 4, 220223. doi:10.1038/sj.embor.embor781

[52] Scoones, I. and Thompson, J. (1993) Challenging the populist perspective: Rural people's knowledge, agricultural research and extension practice. Institute of Development Studies, Brighton.

[53] Watson, A., Alessa, L. and Glaspell, B. (2003) The relationship between traditional ecological knowledge, evolving cultures, and wilderness protection in the circumpolar north. Conservation Ecology, 8, 2-21.

[54] Kabananukye, I. (1996) Population dynamics of Abayanda pygmies of south western Uganda. Paper Presented at Cultural Research at University of Nairobi, 23-26 August 1996. 
[55] Stacey, T. (1996) Bakonzo identity and the protection of Rwenzori: The spiritual factor. In: Osmaston, H., Tukahirwa, J., Basalirwa, C. and Nyakana, J., Eds., The Rwenzori Mountains National Park, Makerere University, Kampala, 67-82.

[56] Foltz, R.C. (2003) Does nature have historical agency? World history, environmental history, and how historians can help save the planet. History Teacher, 37, 9-28. doi: $10.2307 / 1555594$

[57] Fisher, M. (2004) Household welfare and forest dependence in southern Malawi. Environment and Development Economics, 9, 135-154. doi:10.1017/S1355770X03001219
[58] Mamo, G., Sjaastad, E. and Vedeld, P. (2007) Economic dependence on forest resources: A case from Dendi District, Ethiopia. Forest Policy and Economics, 9, 916-927. doi:10.1016/j.forpol.2006.08.001

[59] Vedeld, P., Angelsen, A., Sjaastad, E. and Kobugabe, B.G (2007) Forest environmental incomes and the rural poor. Forest Policy and Economics, 9, 869-879. doi:10.1016/j.forpol.2006.05.008

[60] Coulibaly-Lingani, P., Savadogo P., Tigabu, M. and Oden, P. (2011) Factors influencing people's participation in the forest management program in Burkina Faso, West Africa. Forest Policy and Economics, 13, 292-302. doi:10.1016/j.forpol.2011.02.005 